\title{
Repairing the rheumatic mitral valve in the young. The horizon revisited
}

Chandrasekaran Ananthanarayanan, $\mathrm{MCh},{ }^{\mathrm{a}}$ Amber Malhotra, $\mathrm{MCh},{ }^{\mathrm{a}} \mathrm{Sumbul}$ Siddiqui, $\mathrm{MCh},{ }^{\mathrm{a}}$ Pratik Shah, MSc, ${ }^{\mathrm{b}}$ Himani Pandya, MSc, ${ }^{\mathrm{b}}$ Pranav Sharma, MCh, ${ }^{\mathrm{a}}$ Anand Shukla, DM, ${ }^{\mathrm{c}}$ and Rajesh Thosani, MD ${ }^{\mathrm{d}}$

\section{ABSTRACT}

Objective: Most of the rheumatic mitral valve repair literature focuses on older patients with burnt out disease. We present our midterm results of rheumatic mitral valve repair in young patients.

Methods: In this retrospective-prospective study, 106 consecutive children ( $<18$ years) underwent mitral valve repair for rheumatic etiology (2013-2017). Patients were evaluated at regular intervals.

Results: The mean age of the cohort was $13.1 \pm 3.2$ years; 30 (29.6\%) patients had recent rheumatic activity $(<8$ weeks); $80(78.4 \%)$ had mitral regurgitation; 8 $(7.8 \%)$ had mitral stenosis; $14(13.7 \%)$ had mixed lesions; 11 underwent emergency surgery for intractable heart failure; and 34 (33.3\%) patients underwent autologous pericardial augmentation. All patients underwent annuloplasty (ring, band, or other); $40(39.2 \%)$ required chordal procedures. Operative mortality was $1 \%$. Mean follow-up was $25.6 \pm 9.5$ months and was $100 \%$ complete. At last follow-up, mean mitral regurgitation grade was $1.2 \pm 0.3$, mean mitral valve gradient was $2.96 \pm 0.18$, and $94.8 \%$ of patients were in New York Heart Association class I. Four patients developed recurrent rheumatic carditis (resulting in severe mitral regurgitation), but there were no thromboembolic or hemorrhagic events. Actuarial survival and freedom from reoperation at 2.5 years were $96.2 \%$ (number at risk, 38), and 97.1\% (number at risk, 38), respectively.

Conclusions: Rheumatic valves in children are eminently repairable. The surgeon who ventures to repair a rheumatic mitral valve should consider all lesions of the various components of the mitral valvular apparatus and must have numerous techniques in the armamentarium to effect a successful repair. (JTCVS Open 2020;1:20-8)

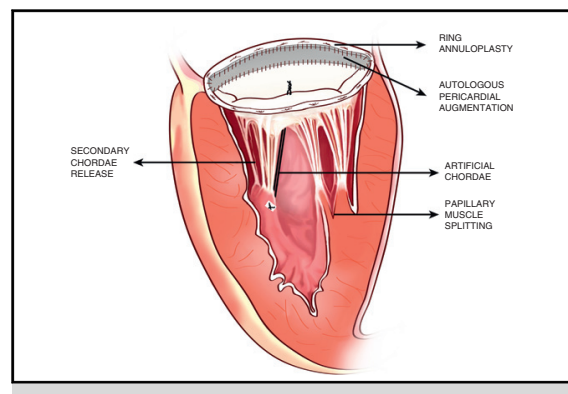

Guiraudon incision offers excellent exposure to all the components of the mitral valve even in small children.

\section{CENTRAL MESSAGE}

Rheumatic mitral valves in chil-

dren are repairable with good

results. Intractable heart failure in

presence of acute rheumatic

carditis does not preclude a

successful repair.

\section{PERSPECTIVE}

Rheumatic mitral repair in children is a challenging entity. Deciphering the problems of the various components of the valvular apparatus and addressing them individually is imperative for a successful repair. Pericardial augmentation is a viable technique in repairing these tissue deficient valves.

See Commentaries on pages 29 and 31.
From the Departments of ${ }^{a}$ Cardiovascular and Thoracic Surgery, ${ }^{b}$ Research, ${ }^{\mathrm{c} C}$ ardiology, ${ }^{\mathrm{d}}$ Cardiac Anesthesia, U. N. Mehta Institute of Cardiology and Research Center, BJ Medical College, Ahmedabad, India.

No external funding sources were used in this study.

Read at the 99th Annual Meeting of The American Association for Thoracic Surgery, Toronto, Ontario, Canada, May 4-7, 2019.

Amber Malhotra is now with Cleveland Clinic, Cleveland, Ohio.

Received for publication Feb 10, 2020; revisions received Feb 10, 2020; accepted for publication Feb 26, 2020; available ahead of print April 10, 2020.

\footnotetext{
Address for reprints: Amber Malhotra, MCh, Department of Cardiovascular and Thoracic Surgery, U. N. Mehta Institute of Cardiology and Research Center, Civil Hospital Campus, Asarwa, Ahmedabad-380016, Gujarat, India (E-mail: drambermalhotra1@gmail.com). 2666-2736

Copyright $(2) 2020$ by The Authors. Published by Elsevier Inc. on behalf of The American Association for Thoracic Surgery. This is an open access article under the CC BY-NC-ND license (http://creativecommons.org/licenses/by-nc-nd/4.0/). https://doi.org/10.1016/j.xjon.2020.02.006
} 


\section{Abbreviations annd Acronyms}
$\mathrm{ABB}=$ Abbreviation
AML = anterior mitral leaflet
PML = posterior mitral leaflet
$\mathrm{MR}=$ mitral regurgitation
NYHA $=$ New York Heart Association

Video clip is available online.

The prevalence of rheumatic fever in India among school children in the age group of 5 to 16 years is 6 in 1000 (range, $1.8 / 1000-11 / 1000),{ }^{1}$ and is the leading cause of mitral valve disease in young people. The mitral annulus in young patients is usually small, and valve replacement at a younger age is likely to result in patient-prosthesis mismatch later in life. Both mechanical and bioprosthetic valve replacements in young patients come with their own sets of problems. Mechanical prostheses condemn patients to anticoagulation for life, battling with problems of thromboembolism and bleeding, whereas bioprosthetic valves degenerate rapidly. Both types of valve replacements will need re-replacement even in an uneventful course, as either the child will outgrow the prosthesis or the prosthesis will degenerate. ${ }^{2}$ Bioprosthetic valve replacement in a small annulus is not a hemodynamically favorable operation, and is fraught with complications, such as left ventricle rupture and left ventricular outflow tract obstruction. ${ }^{3}$ All these drawbacks should motivate surgeons to always repair mitral valves in children; however, most surgeons avoid repairing rheumatic valves in the young for fear of failure, because unlike adults, they do not present in the stable chronic phase of the disease (ie, young patients are not yet in the burnt-out phase). We propose to analyze our midterm results of rheumatic mitral valve repair in a young patient population.

\section{MATERIALS AND METHODS \\ Study Design}

This is a retrospective-prospective study of 106 consecutive patients younger than 18 years who underwent mitral valve surgery for rheumatic etiology at our institution between December 2013 and December 2017. The study was approved by the institution's ethics committee.

Inclusion criteria. All patients younger than 18 years who underwent mitral valve repair for rheumatic etiology were included in the study. Patients who underwent additional procedures on the tricuspid or aortic valve were also included in the study.

Exclusion criteria. All types of mitral valve repairs for nonrheumatic etiology were excluded from the study.

Groups. The entire cohort was divided into two groups. Group 1 consisted of patients with non-stenotic lesions ( $\mathrm{n}=80 ; 78.4 \%$ ), whereas group 2 consisted of patients with stenotic lesions $(\mathrm{n}=22 ; 21.6 \%)$.

\section{Conduct of Surgery}

All patients were operated on by the same surgeon (A.M.) through median sternotomy (Video 1). Transesophageal echocardiography was used in all cases to guide and assess the adequacy of repair. Cardiopulmonary bypass was instituted with aortobicaval cannulation, and surgery was performed under moderate hypothermia. The mitral valve was exposed by Guiraudon's approach. ${ }^{4}$ After detailed assessment of the lesions, various techniques were used to repair the mitral valve. When pericardial augmentation was needed, the pericardium was harvested, and all the overlying fat and soft tissues were diligently cleaned away. We believe cleaning all the fat and adjacent redundant tissues from the pericardium is very important in preventing delayed fibrosis and degeneration of autologous pericardium. The pericardium was stretched on a metal platform and fixed with $0.6 \%$ glutaraldehyde for 3 minutes. This 3-minute fixation period seems to allow a good pliability matching with the native tissue leaflets in our young subset of patients. In cases of tissue deficiency caused by fibrosis or that created after excision of calcified areas, the defects were filled with autologous pericardium. In some of the very young patients, the leaflets were augmented to allow a relatively bigger ring to be placed, thus avoiding gradients at a later stage in the growing child. The leaflet to be augmented was detached from the annulus from one commissure to the other. The required length and breadth of pericardium were measured from this defect, which was created after allowing a coaptation of $1 \mathrm{~cm}$ with the other leaflet. The pericardial patch was fashioned in an eye-shaped configuration for the anterior mitral leaflet (AML) and in a quadrangular configuration with the longer side toward the free margin for the posterior mitral leaflet (PML). The patch was sutured along the circumference of the leaflet, first at the annular margin and then at the free margin of the disconnected leaflet, with continuous 4-0 or 5-0 polypropylene sutures. In addition, interrupted polypropylene sutures were placed at the transition points and at the midpoints of the suture line. A successful repair was considered to be one that resulted in less than mild mitral regurgitation (MR) and mean gradient of less than $5 \mathrm{~mm} \mathrm{Hg}$ for the mitral valve, with not more than mild regurgitation for the tricuspid and aortic valves. Weaning from cardiopulmonary bypass, chest closure, and use of inotropes were handled according to standard institutional protocols.

\section{Follow-up Visits}

All patients were discharged on penicillin prophylaxis for secondary prevention and optimal medical therapy according to our institution's protocols. Strict follow-up was maintained, with significant stress on

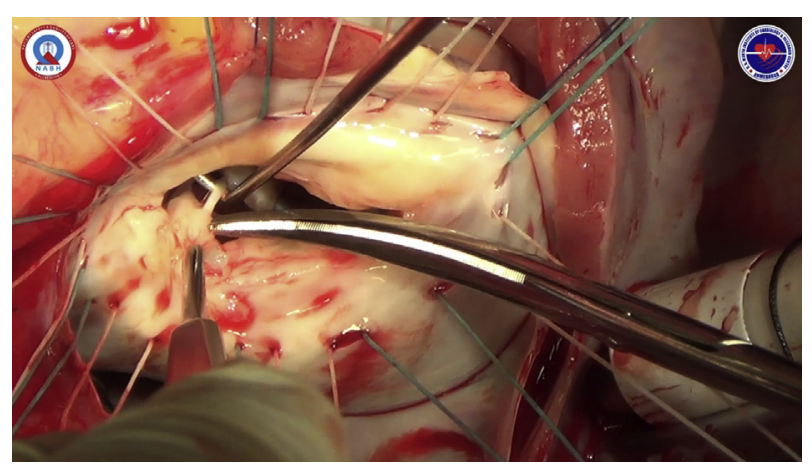

VIDEO 1. Edited video demonstrating the assessment of valve and important steps of repair. Video available at: https://www.jtcvs.org/ article/S2666-2736(20)30008-5/fulltext. 
TABLE 1. Demographic characteristics

\begin{tabular}{lcccc}
\hline & $\begin{array}{c}\text { Total } \\
(\mathbf{N = 1 0 2})\end{array}$ & $\begin{array}{c}\text { Group 1 } \\
(\mathbf{N}=\mathbf{8 0})\end{array}$ & $\begin{array}{c}\text { Group 2 } \\
(\mathbf{N = 2 2})\end{array}$ & $\begin{array}{c}\boldsymbol{P} \\
\text { value }\end{array}$ \\
\hline Age (y) & $13.1 \pm 3.2$ & $12.9 \pm 3.5$ & $14.4 \pm 3.2$ & .096 \\
Sex & & & & .809 \\
$\quad$ Male & $51(50)$ & $39(48.8)$ & $12(54.5)$ & \\
$\quad$ Female & $51(50)$ & $41(51.2)$ & $10(45.4)$ & \\
Weight (kg) & $29.7 \pm 8.9$ & $29.0 \pm 9.2$ & $32.0 \pm 7.6$ & .175 \\
BSA & $1.2 \pm 0.4$ & $1.1 \pm 0.4$ & $1.3 \pm 0.4$ & .208 \\
NYHA functional class & & & & \\
$\quad$ II & $20(19.6)$ & $18(22.5)$ & $2(9.1)$ & .333 \\
$\quad$ III & $71(69.6)$ & $53(66.3)$ & $18(81.8)$ & .252 \\
$\quad$ IV & $11(10.8)$ & $9(11.3)$ & $2(9.09)$ & .921 \\
Recent rheumatic activity & $30(29.6)$ & $26(32.5)$ & $4(18.1)$ & .297 \\
\hline Recurrent heart failure & $18(17.6)$ & $15(18.8)$ & $3(13.6)$ & .809 \\
Intractable heart failure & $11(10.8)$ & $9(11.3)$ & $2(9.09)$ & .921 \\
\hline Rhythm $\quad$ & & & & .638 \\
$\quad$ Sinus rhythm & $97(95.1)$ & $76(9)$ & $21(95.4)$ & \\
$\quad$ Atrial fibrillation & $5(4.9)$ & $4(5)$ & $1(4.5)$ & \\
\hline
\end{tabular}

Data are n $(\%)$ or mean \pm SD. BSA, Body surface area; NYHA, New York Heart Association.

secondary prophylaxis with penicillin. Transthoracic echocardiography was done at the time of discharge; at 1, 3, and 6 months postoperatively; and yearly thereafter. The lesions were graded according to the 2014 American College of Cardiology and American Heart Association guidelines for valvular heart disease. ${ }^{5}$ The degree of MR was scored as 0 for no or trivial MR; 1 for mild MR, 2 for moderate MR, and 3 for severe MR for analytic purposes. The various events recorded in follow-up were death from any cause, thromboembolic episodes, bleeding complications, infective endocarditis, recurrent carditis, and reoperations.

\section{Analysis of Data}

Continuous variables are presented as mean \pm SD or median with interquartile range. Categorical variables are shown as the percentage of the sample. Comparison between the groups was performed with the Student $t$ test or Fisher exact test as appropriate. Actuarial survival and event-free survival were estimated by the Kaplan-Meier method. The statistical calculations were performed with SPSS software (version 20.0; IBM, Armonk, NY).

\section{RESULTS \\ Demography}

Between December 2013 and December 2017, a series of 106 consecutive patients younger than 18 years underwent mitral valve surgery at our institution. Four patients underwent replacement after failed attempts at repair. The demographic characteristics of the entire cohort and of the groups are given in Table 1 . The mean age of the cohort was $13.1 \pm 3.2$ years. Sex distribution was equal (51 male and 51 female patients). The main presenting symptom was breathlessness on exertion in $83 \%$ of patients. Most of the patients $(\mathrm{n}=82 ; 80.3 \%)$ were in New York Heart Association (NYHA) functional class II or III. Thirty
TABLE 2. Mechanisms of mitral valve lesions, left ventricular indices, and associated lesions

\begin{tabular}{lccc}
\hline \multicolumn{1}{c}{ Variable } & $\begin{array}{c}\text { Group 1 } \\
(\mathbf{n = 8 0})\end{array}$ & $\begin{array}{c}\text { Group 2 } \\
(\mathbf{n = 2 2})\end{array}$ & $\begin{array}{c}\boldsymbol{P} \\
\text { value }\end{array}$ \\
\hline AML prolapse & $20(25)$ & $1(4.55)$ & .071 \\
\hline AML restricted mobility & $18(22.5)$ & $11(50)$ & .023 \\
\hline AML retraction & $11(13.8)$ & $10(45.4)$ & .003 \\
\hline PML prolapse & $6(7.5)$ & - & .416 \\
\hline PML restricted mobility & $30(37.5)$ & $15(68.1)$ & .020 \\
\hline PML retraction & $5(6.3)$ & $5(22.7)$ & .057 \\
\hline Commissural fusion & $7(8.8)$ & $11(50)$ & $<.0001$ \\
\hline Chordal rupture & $8(10)$ & $2(9.0)$ & .781 \\
\hline Chordal retraction & $19(23.8)$ & $13(59.0)$ & .003 \\
\hline Chordal lengthening & $12(15)$ & - & .118 \\
\hline Chordal fusion & $3(3.8)$ & $4(18.1)$ & .058 \\
\hline LVEDD (mm) & $51.6 \pm 8.1$ & $45.6 \pm 9.4$ & .0004 \\
\hline LVESD (mm) & $34.4 \pm 7.4$ & $29.4 \pm 6.5$ & .0005 \\
\hline LVEF (\%) & $49.5 \pm 20.2$ & $52.1 \pm 13.5$ & .571 \\
\hline Significant AR & $12(15)$ & $2(9.09)$ & .716 \\
\hline Significant TR & $42(52.5)$ & $11(50)$ & .973 \\
\hline Dat & &
\end{tabular}

Data are $\mathrm{n}(\%)$ or mean $\pm \mathrm{SD} . A M L$, Anterior mitral leaflet; $P M L$, posterior mitral leaflet; $L V E D D$, left ventricular end-diastolic dimension; $L V E S D$, end-systolic dimension; $L V E F$, left ventricular ejection fraction; $A R$, aortic regurgitation; $T R$, tricuspid regurgitation.

$(29.6 \%)$ patients had evidence of recent rheumatic activity $(<8$ weeks) in the form of raised antistreptolysin-O and $\mathrm{C}$-reactive protein titers and the presence of symptoms despite optimal medical therapy. Eighteen patients $(17.6 \%)$ had at least 1 admission for management of heart failure before surgery. Eleven patients $(10.8 \%)$ were in acute carditis with intractable heart failure despite maximal medical therapy (ie, 2 or more inotropes at maximal dosages), which was beginning to affect the kidney and liver

TABLE 3. Techniques of mitral valve repair

\begin{tabular}{lccc}
\hline \multicolumn{1}{c}{ Technique } & $\begin{array}{c}\text { Group 1 } \\
(\mathbf{n = 8 0 )}\end{array}$ & $\begin{array}{c}\text { Group 2 } \\
(\mathbf{n = 2 2})\end{array}$ & $\begin{array}{c}\boldsymbol{P} \\
\text { value }\end{array}$ \\
\hline AML peeling & $18(22.5)$ & $14(63.6)$ & .0006 \\
PML peeling & $28(35)$ & $16(72.7)$ & .003 \\
\hline Pericardial augmentation & $19(23.7)$ & $15(68.1)$ & .0003 \\
Commissurotomy & $7(8.7)$ & $17(77.2)$ & $<.0001$ \\
Chordal procedure & $35(43.7)$ & $5(22.7)$ & .123 \\
Papillotomy & - & $7(31.8)$ & $<.0001$ \\
Cleft closure & $18(22.5)$ & $9(40.9)$ & .144 \\
Annuloplasty & 80 & 22 & \\
Total number of repair procedures & 205 & 105 & \\
Repair procedures per patient & $2.55 \pm 1.68$ & $5 \pm 3.12$ & $<.0001$ \\
\hline
\end{tabular}

Data are $\mathrm{n}(\%)$ or mean $\pm \mathrm{SD} . A M L$, Anterior mitral leaflet; $P M L$, posterior mitral leaflet. 
TABLE 4. Perioperative outcomes

\begin{tabular}{lcccc}
\hline & $\begin{array}{c}\text { Total } \\
(\mathbf{N}=\mathbf{1 0 2})\end{array}$ & $\begin{array}{c}\text { Group 1 } \\
(\mathbf{n = 8 0})\end{array}$ & $\begin{array}{c}\text { Group 2 } \\
(\mathbf{n = 2 2})\end{array}$ & $\begin{array}{c}\boldsymbol{P} \\
\text { value }\end{array}$ \\
\hline CPB time (min) & $145.2 \pm 48.5$ & $141.1 \pm 48.0$ & $160.1 \pm 48.2$ & .106 \\
$\begin{array}{l}\text { Crossclamp time } \\
(\text { min) }\end{array}$ & $113.9 \pm 41.6$ & $108.9 \pm 39.3$ & $131.9 \pm 45.6$ & .021 \\
Ventilation (h) & $6.5(9)$ & $8(9)$ & $5(8)$ & .653 \\
ICU stay (d) & $4(2)$ & $4(2)$ & $4(2)$ & .667 \\
\hline Hospital stay (d) & $9(4)$ & $9(4)$ & $8.5(3.5)$ & .980 \\
\hline Operative mortality & $1(1 \%)$ & 1 & 0 & .487 \\
\hline Data are n (\%) or mean + SD. $C P B$, Cardiopulmonary bypass; $I C U$, intensive care unit.
\end{tabular}

function. These patients therefore had to undergo urgent surgery. Five $(4.9 \%)$ patients were in chronic atrial fibrillation before surgery.

\section{Lesion Complexity}

The complexity of lesions was scored according to our CLAS Complexity Score. ${ }^{6}$ The 4 subunits: (commissure, leaflet, annulus, and subvalvular apparatus) were combined to give the score. ${ }^{6}$

The lesions were given the final score intraoperatively. The lesions of various components of the mitral apparatus (commissures, leaflet, annulus, subvalvular apparatus) are given in Table 2. Most of the patients had lesions of more than 1 component of the mitral valve. The patients in the stenotic group needed a higher number of procedures on various valvular subunits for a complete repair $(5 \pm 3.12$ vs $2.55 \pm 1.68 ; P=.0001)$. The mean CLAS score of the stenotic group (group 2) was 10.3, versus 6.8 for the nonstenotic or regurgitant group (group 1), buttressing the fact that stenotic lesions required a procedure to be carried out on more subunits of the valve than did the regurgitant lesions (Table 3). Although most lesions occurred in both the groups, there were some trends within each group. Leaflet prolapse and chordal rupture or elongation were mainly present in the nonstenotic lesions, whereas commissural fusion, chordal fusion or retraction, and papillary muscle fusion were commonly seen in the stenotic lesions (Table 2). The 4 patients with failed repairs had CLAS scores of at least $12(12,13,12$, and 14).

\section{Surgical Techniques}

As expected, most of the patients required correction of multiple components of the valve (Table 2). Table 3 shows the various surgical techniques and their comparisons between the 2 groups. Chordal procedures were more commonly used in group 1 (non- stenotic; $\mathrm{n}=35$; $43.7 \%)$ than in group $2(\mathrm{n}=5 ; 22.7 \%)$. Leaflet thinning (peeling with or without shaving), leaflet augmentation, commissurotomy, and papillary muscle splitting were commonly used in group 2 (stenotic). Pericardial augmentation of the leaflets was done in 34 patients $(33.3 \%)$
TABLE 5. Midterm outcomes for entire cohort $(\mathrm{N}=102)$

\begin{tabular}{lcccr}
\hline & Preoperative & $\begin{array}{c}\text { Immediate } \\
\text { postoperative }\end{array}$ & $\begin{array}{c}\text { Last } \\
\text { follow-up }\end{array}$ & $\begin{array}{c}\boldsymbol{P} \\
\text { value }\end{array}$ \\
\hline LVEF $(\%)$ & $50.2 \pm 18.9$ & $49.2 \pm 9.9$ & $53.3 \pm 5.1$ & .002 \\
LVEDD (mm) & $50.3 \pm 8.7$ & $48.49 \pm 7.0$ & $46.7 \pm 5.1$ & $<.001$ \\
\hline LVESD (mm) & $33.3 \pm 7.5$ & $31.79 \pm 6.5$ & $30.9 \pm 4.9$ & $<.002$ \\
$\begin{array}{l}\text { Mean mitral } \\
\text { gradient } \\
\text { (mm Hg) }\end{array}$ & $2.6 \pm 3.7$ & $1.6 \pm 0.2$ & $2.9 \pm 0.18$ & .399 \\
MR grade & $3(1)$ & $3(1)$ & & \\
\hline
\end{tabular}

Data are n $(\%)$ or mean \pm SD. $L V E F$, Left ventricular ejection fraction $L V E D D$, left ventricular end-diastolic dimension; LVESD, left ventricular end-systolic dimension; $M R$, mitral regurgitation.

when there was significant leaflet tissue deficit (referred to as AML or PML retraction). All the repairs were supported by an annuloplasty. The median size of the mitral ring used was 26 (range, 24-30). For smaller annuli, the repair was supported by a posterior band annuloplasty. Tricuspid valve repair was done in 53 patients $(51.9 \%)$, and aortic valve repair was done in $14(13.7 \%)$.

\section{Perioperative Outcomes (Table 4)}

The mean cardiopulmonary bypass and aortic crossclamp times of the entire cohort were $145.2 \pm 48.5$ and $113.9 \pm 41.6$ minutes, respectively. These times were expectedly higher in the stenotic subgroup; however, only the difference in aortic crossclamp time reached statistical significance. The mean ventilation time was $9.5 \pm 9.7$ hours, and the mean intensive care unit and hospital stays were $4.4 \pm 2.6$ and $9.7 \pm 4.8$ days, respectively (the groups were statistically similar). Eleven patients underwent urgent surgery because they had active carditis with intractable heart failure despite maximal medical therapy and, expectedly, these patients had protracted intensive care unit $(P=.04)$ and hospital $(P<.001)$ stays relative to the elective surgical patients.

\section{Operative Mortality}

One child with active carditis and intractable heart failure who underwent urgent surgery had persistent low cardiac output syndrome and died on postoperative day 4 . Operative mortality was $1 \%$.

\section{Follow-up}

The mean follow-up was $25.6 \pm 9.5$ months. The events were recorded according to the standard guidelines for reporting results of valvular heart surgery. ${ }^{7}$

\section{Indices (Table 5)}

As expected, many patients with significant MR had left ventricular dysfunction after MR correction in the early postoperative period, but they showed improvement of LV function in the follow-up studies. The left ventricular 


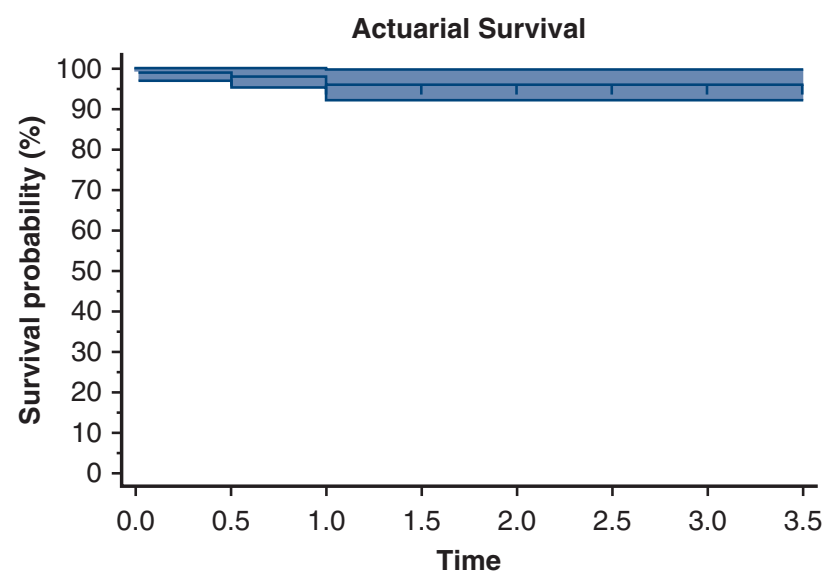

Number at risk

$\begin{array}{llllllll}101 & 97 & 93 & 90 & 44 & 38 & 2 & 0\end{array}$

FIGURE 1. Actuarial survival curve for the entire cohort.

ejection fraction of the entire cohort at the last follow-up was better than their preoperative state (preoperative vs postoperative, $50.2 \% \pm 18.9 \%$ vs $53.3 \% \pm 5.1 \%$; $P=.002)$. The left ventricular dimensions also improved after surgery. Both left ventricular end-diastolic dimension (preoperative vs postoperative, $50.3 \pm 8.7 \mathrm{~mm}$ vs $46.7 \pm 5.0 \mathrm{~mm} ; P<.001)$ and left ventricular end-systolic dimension (preoperative vs postoperative, $33.3 \pm 7.5 \mathrm{~mm}$ vs $30.9 \pm 4.9 \mathrm{~mm} ; P<.002)$ showed significant reduction.

\section{Thromboembolism, Hemolysis, and Bleeding}

No episodes of thromboembolism, hemolysis, or bleeding were seen in our patients.

\section{NYHA Functional Class}

On their last follow-up visit, 5 patients $(4.9 \%)$ had significant MR (4 had moderate MR and 1 had severe

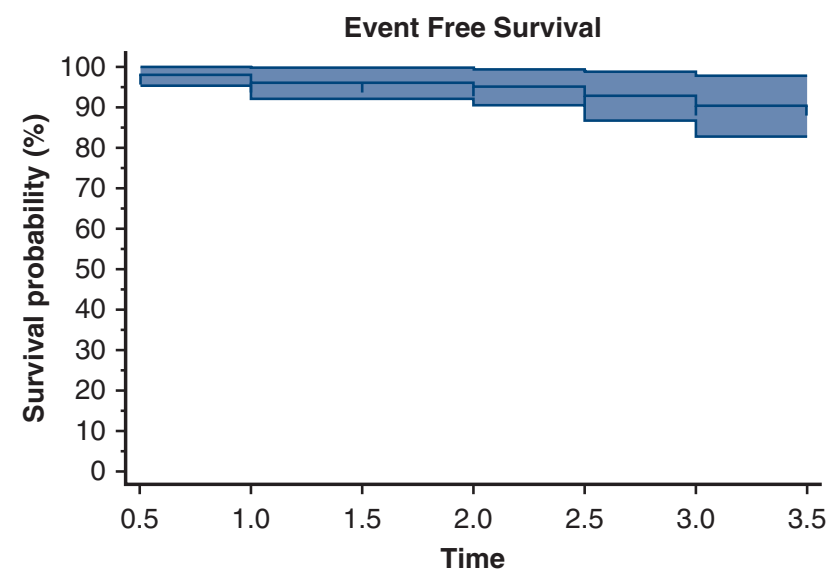

Number at risk

FIGURE 2. Event free survival curve for the entire cohort.
MR) and were in NYHA functional class II. All other survivors are in NYHA functional class I.

\section{Actuarial Survival}

There was 1 operative death, and 3 patients died at various intervals after the primary surgery. The remainder of the survivors are in regular follow-up with us. The actuarial survivals of the entire cohort were $96 \%$ at 1 year (number at risk, 93), 96\% at 2 years (number at risk, 44), and $96 \%$ at 3 years (number at risk, 2; Figure 1).

\section{Event-Free Survival}

Four patients developed recurrent carditis, and 3 developed infective endocarditis. The event-free survivals of the entire cohort were $96 \%$ at 1 year (number at risk, 93), $94.9 \%$ at 2 years (number at risk, 44 ), and $90.3 \%$ at 3 years (number at risk, 2; Figure 2).

\section{Infective Endocarditis}

One patient (in group 2) developed streptococcal infective endocarditis of the mitral valve 3 months after surgery. At the redo surgery, the AML was found to be destroyed, and the pericardial patch had dehisced significantly. This patient underwent a mitral valve replacement (mechanical valve prosthesis). The remaining 2 patients had development of infective endocarditis (organism not known) at 10 months and 1 year after surgery, were treated medically elsewhere; however, both died of heart failure (Figure 3).

\section{Recurrent Carditis}

Four patients developed recurrent carditis and presented with fever, raised antistreptolysin-O and C-reactive protein titers, and heart failure. The first patient developed recurrent carditis 4 months after surgery, was treated elsewhere, and died of the disease. The second and third patients underwent redo surgery, and the pericardial patch used for augmentation was found to have dehisced in both. The pericardial patch was inflamed by the recurrent disease but was found to be pliable. Both of these patients underwent successful rerepair. The fourth patient had recurrent carditis 1 year after surgery; had development of moderate MR, aortic regurgitation, and tricuspid regurgitation (treated with antifailure medications) and is currently in follow-up. On enquiry, all 4 were found not to have taken their secondary penicillin prophylaxis (Figure 3).

\section{Freedom From Reoperation}

Three patients underwent reoperations at various intervals after their initial surgery, as previously mentioned. The freedoms from reoperation were at $99 \%$ at 1 year (number at risk, 93), 97.9\% at 2 years (number at risk, 44 ), and $95.7 \%$ at 3 years (number at risk, 2; Figure 4). 

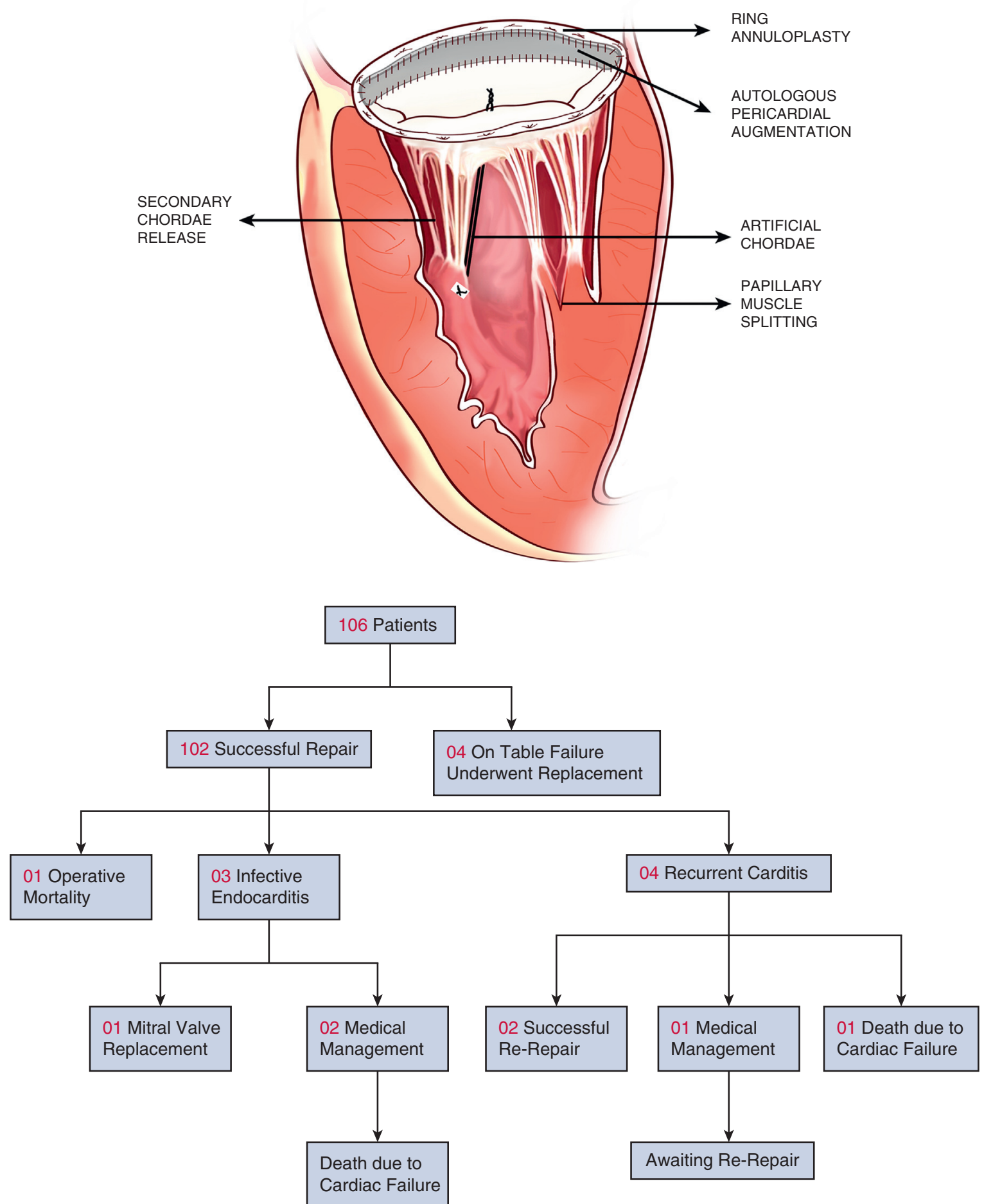

FIGURE 3. Depicts the successes and failures of repairs in our cohort of patients. Out of 106 repairs, 4 repairs failed on the operating table (more than mild mitral regurgitation and $>5 \mathrm{~mm} \mathrm{Hg}$ gradient across mitral valve), necessitating valve replacement. There were 1 early death and 7 failures, 4 from recurrent carditis and 3 from infective endocarditis.

\section{Valve Function}

Other than the 7 patients mentioned in the events section, 4 patients had development of significant MR (3 moderate and 1 severe). At a mean follow-up of $25.6 \pm 9.5$ months, most of patients $(89.2 \%)$ were free of significant MR. The mean MR grade and the average mean mitral valve gradient of the entire cohort were $1.2 \pm 0.3$ and $2.9 \pm 0.1 \mathrm{~mm} \mathrm{Hg}$, respectively, at the last follow-up 


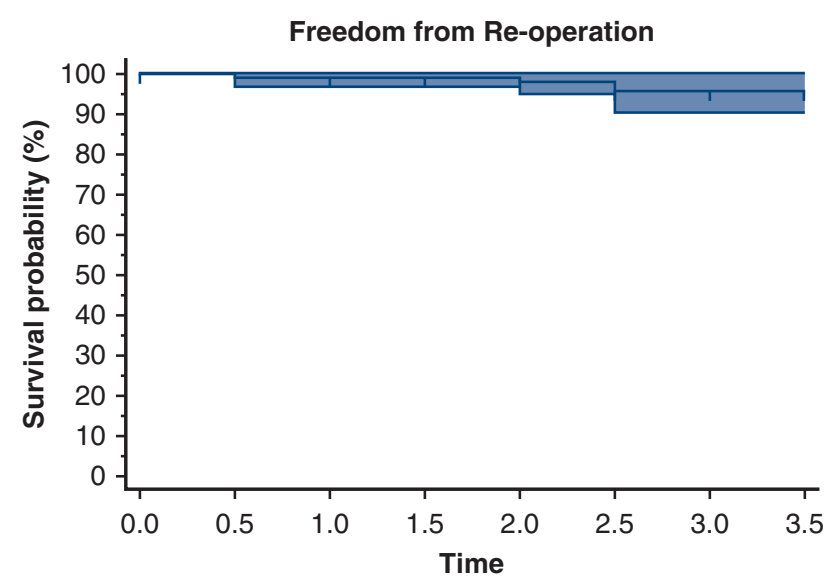

Number at risk

$\begin{array}{llllllll}100 & 96 & 93 & 90 & 44 & 38 & 2 & 0\end{array}$

FIGURE 4. Freedom from reoperation curve for the entire cohort.

(Table 5). The postoperative MR grade was similar between the stenotic and the nonstenotic groups $(P=.43)$. The average mean mitral gradient was higher in group 2 (stenotic) than in group 1 (nonstenotic; $3.2 \pm 0.6$ vs $1.5 \pm 0.8 \mathrm{~mm} \mathrm{Hg} ; P<.001)$. Patients, who underwent aortic and tricuspid valve repairs were also free of significant recurrences.

\section{Pericardial Augmentation of Leaflets}

Thirty-four $(33.3 \%)$ patients underwent autologous pericardial augmentation of either or both leaflets. Three $(8 \%)$ among them underwent redo surgery for reasons previously mentioned. At their last follow-up, those with augmented repairs had similar MR grades $(P=.73)$ but higher gradients than those with nonaugmented repairs $(4.3 \pm 4.4$ vs $2.9 \pm 4.6 ; P=.15)$. Augmentation was more common in the stenotic subgroup than in the nonstenotic subgroup ( $68 \%$ vs $23.7 \% ; P=.0003)$.

\section{DISCUSSION}

Mitral valve repair obviates many problems of replacement, such as anticoagulation, thromboembolism, infective endocarditis, prosthetic valve thrombosis and degeneration. ${ }^{8}$ Valve replacement carries high mortality and morbidity, especially in young patients, with operative mortality as high as $16.3 \%$ (our series, $0.98 \%$ ), actuarial survival of $89 \%$ (our series, $96.2 \%$ ), event-free survival of $52 \%$ (our series, $92.2 \%$ ). ${ }^{9,10}$ Some complications are exclusive to replacement, or almost so, such as perivalvular leak $(15 \%)$, prosthetic valve thrombosis $(3 \%)$, pacemaker implantation (5\%), and bleeding $(5 \%)$. Valve replacement is therefore generally considered as replacement of one disease with another. ${ }^{9} 10$

Ventricular function is better preserved and restored by repair than by replacement. ${ }^{11}$ The results of repair are extremely promising for many of the nonrheumatic pathologies, such as Barlow syndrome, cleft mitral valve, and partial atrioventricular septal defects. ${ }^{12}$ All these pathologies are associated with plenty of mitral leaflet tissue, and thus many types of repair techniques can be planned and executed, unlike in rheumatic pathology, where the tissue deficit limits the surgeon's options.

Classically, the chronic valvular lesions of rheumatic heart disease in adults are slowly progressive. Unlike adults, children have multiple acute exacerbations in the chronic course of the disease and usually present with lesions which are a mix of Carpentier type II and III pathologies. This is seen in our study population as well, with some patients having a retracted PML (type IIIA) along with prolapse of the AML (type II; Table 2). As the PML gets retracted due to the disease process, the AML appears prolapsed (pseudoprolapse) in the initial phases. Later, as the result of the excessive pressure borne by the AML (due to noncoaptation), the AML chordae elongate, leading to a true prolapse. Superimposed recurrent carditis can complicate these mechanisms further.

We believe that surgical exposure is a key factor in the success of such challenging procedures and Guiraudon's approach $^{4}$ provides the best exposure, especially in young patients with small hearts. Tricuspid valve procedures can also be done through the same incision. Even though the sinoatrial nodal artery was injured in a few patients, we have not encountered sinus node dysfunction in any patient, probably because of the rich plexus of arteries in this region.

Initial surgical series have mainly addressed the annulus in repairing the mitral valve. ${ }^{13,14}$ Very few groups have reported techniques to tackle the mitral apparatus as a whole. ${ }^{15-17}$ We believe that it is imperative to study the pathologic contributions of each component of the mitral valve apparatus, such as papillary muscle, chordae, commissure, leaflet, and annulus, and then address them individually to deliver good results. We have devised a scoring system named CLAS (commissure, leaflet, annulus, and subvalvular apparatus) to quantify the lesions and plan repair techniques accordingly. Patients with a higher CLAS score (more than 8) pose challenges in repair and may require multiple repair techniques. ${ }^{6}$ Patients with a CLAS score more than 12 are expected to have higher on-table failures. Four of our patients with repair failure had high CLAS scores (more than 12). The CLAS score has a prognostic value and thus can allow the surgeon to be aggressive in certain cases, where repair is easy and long-term results likely, and cautious in other cases (perhaps timely aborting attempts at repair), where the early and late results may not justify the prolonged cardiopulmonary bypass time in a sick child. In addition, it does give the patient some idea about the expected longevity of repair.

Leaflet thickening starts with a layer of fibrous plaque over the left atrial surface, and as the fibrosis progresses, 
the leaflet thickens and shrinks, leading to significant loss of tissue for coaptation as well as for surgical repair. When the fibrous plaque is less adherent (leaflet thickened with restricted mobility; Table 2), the fibrous layer can be peeled off the leaflet to release it. For leaflets with dense fibrosis and significant tissue loss (fibrotic or calcified leaflets; Table 2), we have resorted to leaflet thinning (peeling, shaving, or excising) and augmentation of the residual leaflet with glutaraldehyde-treated autologous pericardium. Two of our patients who underwent PML augmentation had high gradients at 2 years of follow-up (mean gradients of 8 and $9 \mathrm{~mm} \mathrm{Hg}$ ). PML augmentation should be planned with extreme caution, because it can cause postoperative inflow gradients, especially in patients with some amount of valvular stenosis. McGurty and collagues $^{18}$ recently published their impressive results in young patients with rheumatic heart disease. Most of their patients had advanced mitral insufficiency, however, and thus peeling, shaving, and excision did not figure very prominently in their list of procedures. They also caution against the use of posterior pericardial augmentation in Carpentier type III lesions. ${ }^{18}$

Even though pericardial augmentation is a less popular option among the various methods of mitral repair, ${ }^{19}$ we consider it extremely useful, especially in treating lesions with rheumatic etiology. It has expanded the possibility of repair to severely stenosed valves as well. Even though the augmented valves had higher gradients than the nonaugmented repairs, the MR grade was similar to that of nonaugmented valves at 2 years of follow-up. On redo surgery, the pericardium was found pliable in all patients. The inflammation caused by recurrent carditis can cause dehiscence of the patch. In our early experience, the pericardium was attached to the residual leaflet with a single layer of polypropylene suture, and we attribute the easy dehiscence (when afflicted with recurrence of carditis or infective endocarditis) to this. Our successful repair rate was $96.2 \%$ (almost one-third needed pericardial augmentation). These patients would have potentially undergone valve replacement had the option of pericardial augmentation not been available. Recombinant tissue substitutes might take pericardium's place in the future; as of now, however, pericardial augmentation is a very useful technique in the armory of the repair surgeons.

Most of the surgical literature on rheumatic mitral valve repair is about the older age group of patients who are in the chronic and burnt out phase of the disease. ${ }^{11,20-23}$ Ours is one of the few studies which has a sizeable proportion of patients $(n=30 ; 29.6 \%)$ in acute and subacute phase of the disease. We try to wait for the child to have recovered from acute rheumatic fever for 8 weeks before we plan surgery; in cases of intractable heart failure, however, it sometimes becomes imperative to intervene, even at the cost of higher morbidity.
We took extreme precautions in these patients by putting several additional neochords in multiple seemingly normal areas to prevent future chordal ruptures and MR. Leaflet augmentation suture lines were reinforced with additional interrupted sutures to prevent dehiscence of the patch even when it becomes inflamed by episodes of rheumatic fever in the future. Rheumatic heart disease is an autoimmune process with long-term consequences. ${ }^{24,25}$ We try to ensure compliance with secondary penicillin prophylaxis for all our patients, as per guidelines, on an outpatient visit basis. ${ }^{26}$ We believe that strict adherence to secondary prophylaxis is imperative to reduce the incidence of recurrence, because we have found that those patients who had a recurrence in our study group were noncompliant with secondary penicillin prophylaxis.

\section{Limitations}

The retrospective nature and the relatively short follow-up are significant limitations of our study. A longer follow-up of these patients will be more informative about the recurrence of carditis, repair failures, and event-free survival.

\section{CONCLUSIONS}

Rheumatic valves in children are eminently repairable. The surgeon who ventures to repair a rheumatic mitral valve should consider all the lesions of the various components of the mitral valvular apparatus and must have numerous techniques in his or her armamentarium to effect a successful repair.

\section{Webcast}

You can watch a Webcast of this AATS meeting presentation by going to: https://aats.blob.core.windows.net/media/19\% 20AM/Sunday_May5/205BD/205BD/S39\%20-\%20Mitral \%20Valve\%20Repair\%20Essentials/S39_10_webcast_ 091623503.mp4.

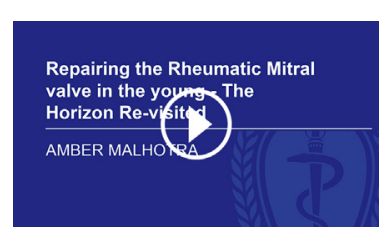

\section{Conflict of Interest Statement}

The authors reported no conflicts of interest.

The Journal policy requires editors and reviewers to disclose conflicts of interest and to decline handling or reviewing manuscripts for which they may have a conflict of interest. The editors and reviewers of this article have no conflicts of interest. 
The authors are grateful to Dr Eugene Blackstone, MD (Cleveland Clinic) for his guidance in preparation of this manuscript. The authors acknowledge the hardwork of Mr Kirtan Patel and Mr Nikunj Solanki (Photography Department, UN Mehta Institute of Cardiology) in preparation of the video and graphics.

\section{References}

1. Shrivastava S. Rheumatic heart disease: is it declining in India? Indian Heart J. 2007;59:9-10.

2. Robbins RC, Bowman FO, Malm JR. Cardiac valve replacement in children: a twenty-year series. Ann Thorac Surg. 1988;45:56-61.

3. el Makhlouf A, Friedli B, Oberhänsli I, Rouge JC, Faidutti B. Prosthetic heart valve replacement in children. Results and follow-up of 273 patients. J Thorac Cardiovasc Surg. 1987:93:80-5.

4. Guiraudon GM, Ofiesh JG, Kaushik R. Extended vertical transatrial septal approach to the mitral valve. Ann Thorac Surg. 1991;52:1058-60; discussion 1060-2.

5. Nishimura RA, Otto CM, Bonow RO, Carabello BA, Erwin JP IV, Guyton RA, et al. American College of Cardiology/American Heart Association task force on practice guidelines. 2014 AHA/ACC guideline for the management of patients with valvular heart disease: a report of the American College of Cardiology/American Heart Association task force on practice guidelines. J Am Coll Cardiol. 2014;63:e57-185. Erratum in: J Am Coll Cardiol. 2014;63:2489.

6. Malhotra A, Siddiqui S, Wadhawa V, Pandya H, Patel K, Shah K, et al. 'CLAS' score: an objective tool to standardize and predict mitral valve repairability. Ind J Thorac Cardiovasc Surg. 2019;35:15-24.

7. Edmunds LH Jr, Clark RE, Cohn LH, Grunkemeier GL, Miller DC, Weisel RD. Guidelines for reporting morbidity and mortality after cardiac valvular operations. Ad hoc liaison committee for standardizing definitions of prosthetic Heart valve morbidity of the American Association for Thoracic Surgery and the Society of Thoracic Surgeons. J Thorac Cardiovasc Surg. 1996;112:708-11.

8. Yau TM, El-Ghoneimi YA, Armstrong S, Ivanov J, David TE. Mitral valve repair and replacement for rheumatic disease. J Thorac Cardiovasc Surg. 2000;119: 53-60.

9. Kojoria F, Chen R, Caldarone CA, Merklinger SL, Azakie A, Williams WG, et al. Outcomes of mitral valve replacement in children: a competing-risks analysis. $J$ Thorac Cardiovasc Surg. 2004;128:703-9.

10. Van Doorn C, Yates R, Tsang V, Elliott M. Mitral valve replacement in children: mortality, morbidity, and haemodynamic status up to medium term follow up. Heart. 2000;84:636-42.

11. Skoularigis J, Sinovich V, Joubert G, Sareli P. Evaluation of the long-term results of mitral valve repair in 254 young patients with rheumatic mitral regurgitation. Circulation. 1994;90(5 Pt 2):II167-74.

12. Lee C, Lee CH, Kwak JG, Park CS, Kim SJ, Song JY, et al. Long-term results after mitral valve repair in children. Eur J Cardiothorac Surg. 2010;37:267-72.
13. Antunes MJ, Magalhaes MP, Colsen PR, Kinsley RH. Valvuloplasty for rheumatic mitral valve disease. A surgical challenge. J Thorac Cardiovasc Surg. 1987; $94: 44-56$.

14. Duran CM, Gometza B, Saad E. Valve repair in rheumatic mitral disease: an unsolved problem. J Card Surg. 1994;9(2 Suppl):282-5.

15. Talwar S1, Rajesh MR, Subramanian A, Saxena A, Kumar AS. Mitral valve repair in children with rheumatic heart disease. J Thorac Cardiovasc Surg. 2005;129:875-9.

16. Kalangos A, Christenson JT, Beghetti M, Cikirikcioglu M, Kamentsidis D, Aggoun Y. Mitral valve repair for rheumatic valve disease in children: midterm results and impact of the use of a biodegradable mitral ring. Ann Thorac Surg. 2008;86:161-9.

17. Chotivatanapong T, Lerdsomboon P, Sungkahapong V. Rheumatic mitral valve repair: experience of 221 cases from Central Chest Institute of Thailand. J Med Assoc Thai. 2012;95(Suppl.8):S51-7.

18. McGurty D, Remenyi B, Cheung M, Engelman D, Zannino D, Milne C, et al. Outcomes after rheumatic mitral valve repair in children. Ann Thorac Surg. 2019;108:792-7.

19. Chauvaud S, Fuzellier JF, Berrebi A, Deloche A, Fabiani JN, Carpentier A. Longterm (29 years) results of reconstructive surgery in rheumatic mitral valve insufficiency. Circulation. 2001;104(12 Suppl-1):I12-5.

20. Kumar AS, Rao PN, Saxena A. Results of mitral valve reconstruction in children with rheumatic heart disease. Ann Thorac Surg. 1995;60:1044-7.

21. Choudhary SK, Talwar S, Dubey B, Chopra A, Saxena A, Kumar AS. Mitral valve repair in a predominantly rheumatic population. Long-term results. Tex Heart Inst J. 2001;28:8-15.

22. Kalangos A, Christenson JT, Beghetti M, Cikirikcioglu M, Kamentsidis D, Aggoun Y. Mitral valve repair for rheumatic valve disease in children: midterm results and impact of the use of a biodegradable mitral ring. Ann Thorac Surg. 2008;86:161-8; discussion 168-9.

23. Krishna Moorthy PS, Sivalingam S, Dillon J, Kong PK, Yakub MA. Is it worth repairing rheumatic mitral valve disease in children? Long-term outcomes of an aggressive approach to rheumatic mitral valve repair compared to replacement in young patients. Interact Cardiovasc Thorac Surg. 2018;28:191-8.

24. Chopra P, Gulwani H. Pathology and pathogenesis of rheumatic heart disease. Indian J Pathol Microbiol. 2007;50:685-97.

25. Guilherme L, Köhler KF, Kalil J. Rheumatic heart disease: mediation by complex immune events. Adv Clin Chem. 2011;53:31-50.

26. Working Group on Pediatric Acute Rheumatic Fever and Cardiology Chapter of Indian Academy of Pediatrics, Saxena A, Kumar RK, Gera RP, Radhakrishnan S, Mishra S, et al. Consensus guidelines on pediatric acute rheumatic fever and rheumatic heart disease. Indian Pediatr. 2008;45:565-73.

Key Words: mitral, valve repair, rheumatic, pediatric, leaflet augmentation, neochords, annuloplasty, commissurotomy 